Check for updates

Cite this: CrystEngComm, 2017, 19, 4166

Received 23rd March 2017,

Accepted 11th May 2017

DOI: 10.1039/c7ce00561j

rsc.li/crystengcomm

\section{Base free transfer hydrogenation using a covalent triazine framework based catalyst $\dagger$}

\author{
A. V. Bavykina, ${ }^{a}$ H.-H. Mautscke, ${ }^{\text {b }}$ M. Makkee, ${ }^{a}$ F. Kapteijn, (D) ${ }^{c}$ \\ J. Gascon (iD *a and F. X. Llabrés i Xamena iD*b
}

Isomerisation of allylic alcohols to saturated ketones can be efficiently catalysed by a heterogeneous molecular system resulting from $1 r^{\text {III }} \mathrm{Cp}$ * anchoring to a covalent triazine framework. The obtained catalysts are active, selective, and fully recyclable.

Transfer hydrogenation (TH) reaction - the addition of hydrogen to an unsaturated group of an organic molecule from a source other than $\mathrm{H}_{2}$ - has been gaining a lot of attention as it is an appealing alternative to direct hydrogenation. ${ }^{1}$ The reasoning behind it is the elimination of pressurised hydrogen and high pressure equipment use. Besides, a conventional hydrogenation catalyst is rarely selective - any present unsaturated or oxidised functional group is exposed to reduction, resulting in, most of the time, a fully hydrogenated product or a mixture of products. Exceptions for highly chemoselective hydrogenation catalysts exist, such as noble metal nanoparticles supported on metal oxides or encapsulated inside metal-organic frameworks. ${ }^{2-4}$ In contrast with conventional hydrogenation, $\mathrm{TH}$ allows the reaction to be performed selectively, aiming for a specific unsaturated bond and leaving the rest of the original molecule intact.

A conventional TH catalyst is a transition metal complex; among different metals, iridium is the most active one. Ir complexes involving a $\mathrm{N}$-heterocycle carbene ligand, ${ }^{5-16}$ or halfsandwich complexes with a $\mathrm{Cp}^{*}$ ligand $^{17-22}$ are typical examples. Moving from soluble organometallic compounds to materials that remain solid under the reaction conditions, facilitates separation and enables recycling. There exist a number of works on heterogeneous TH systems, including magnetic nanoparti-

\footnotetext{
${ }^{a}$ Catalysis Engineering, Delft University of Technology, Delft, Netherlands. E-mail: j.gascon@tudelft.nl

${ }^{b}$ Instituto de Tecnologia Quimica CSIC-UPV, Universidad Politecnica de Valencia, Consejo Superior de Investigaciones Científicas, Valencia, Spain.

E-mail: fllabres@itq.upv.es

${ }^{c}$ Chemical Engineering, TUDelft, Delft, Netherlands

$\dagger$ Electronic supplementary information (ESI) available. See DOI: 10.1039/ c7ce00561j
}

cle- ${ }^{23-26}$ polymer-, ${ }^{27-33}$ graphene- ${ }^{34,35}$ carbon nanotube- ${ }^{36-38}$ silica- ${ }^{39-45}$ zeolite- ${ }^{46-49}$ or oxide-supported ${ }^{50-55}$ catalysts.

Recently, Porous Organic Frameworks (POFs) have been gaining attention within catalytic and other applications. ${ }^{56,57}$ Covalent Triazine Frameworks (CTFs), a subclass of POFs, are highly porous and stable solids made by trimerisation of aromatic nitriles. ${ }^{58,59}$ CTFs are rich in nitrogen functionalities, and their distribution can be varied by using different building blocks. Starting from a pyridine containing building unit, quasibipyridine moieties become available in the final material. Bipyridine is a widely-applied ligand in organometallic chemistry; its presence within a framework enables anchoring of a transition-metal complex. Following this approach, a number of molecular heterogeneous catalysts were developed for a range of different catalytic reactions by several research groups. ${ }^{59-67}$

Recently, we developed a CTF based catalyst which is highly active in the reversible formic acid (FA) dehydrogenation

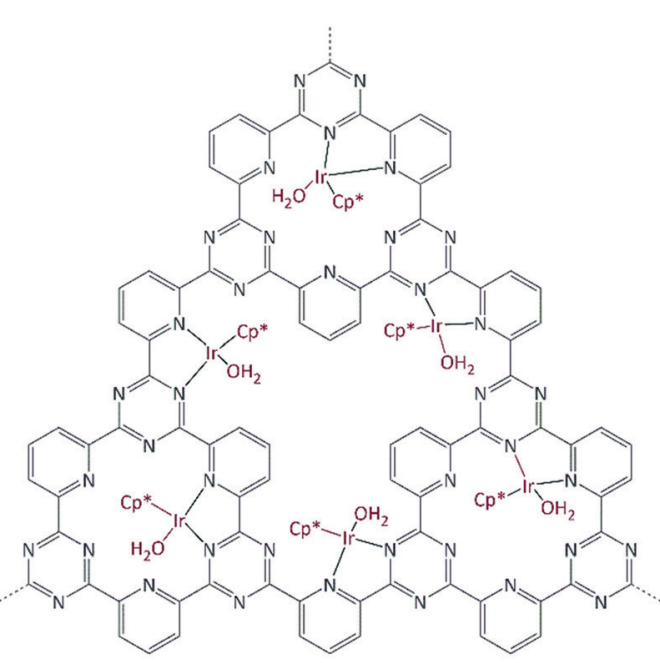

Fig. 1 Idealized representation of the Ir@CTF catalyst. Ir is in the oxidation state $3+$; charges and (OTf $)$ weakly coordinated anions are omitted in the figure for clarity. 
reaction. ${ }^{60,61}$ Applying different conditions, the same catalyst is active in both hydrogen production from FA and hydrogen storage by reaction with carbon dioxide. Both these reactions proceed via iridium-hydride bond formation. In this work, we report the use of a similar Ir@CTF material as a base free catalyst for the transfer hydrogenation (TH) reaction (Fig. 1).

The commercially available iridium precursor $\left[\mathrm{IrCp}^{*} \mathrm{Cl}_{2}\right]_{2}$ is coordinated to bipyridine moieties within the framework, resulting in an air- and moisture-stable Ir@CTF catalyst. The inert atmosphere was required only during the catalyst preparation. Once IrCp* was coordinated, the catalyst can be stored at an ambient atmosphere without losing activity. In order to coordinate iridium to the framework, an aqueous solution of $\left[\mathrm{IrCp} * \mathrm{Cl}_{2}\right]_{2}$ was prepared, in which CTF powder was suspended and stirred. The conventional approach of removing the poisoning chlorine ions by precipitating them with silver cations was ruled out to avoid the precipitation of $\mathrm{AgCl}$ within the pores of the material. Instead, $\mathrm{HCl}$ was complexed with dimethylformamide, and subsequently washed out. ${ }^{68}$ The SEM/ EDX analysis confirmed that no chlorine was present in the final catalyst. Triflic acid was added during the washing steps to enable the charge balance between $\mathrm{Ir}^{3+}$ and weakly coordinated (OTf-) anions. Due to the insoluble nature and the black color of the CTF solids, catalyst characterization was limited to its structural properties, TGA (see Fig. S1 XPS and elemental analysis. The iridium content determined by ICP-OES was $2.4 \mathrm{wt} \%$ Ir in the catalyst. Table 1 summarizes the results of elemental analysis and the BET surface area of CTF and Ir@CTF. The framework employed was constructed solely from pyridinedicarbonitrile, resulting in the fully microporous material. Though the BET surface area decreased after introducing the bulky complex, it was still large enough to be accessible to physisorbed $\mathrm{N}_{2}$. XPS analysis (Fig. 2) indicated that Ir was in the oxidation state $3+,{ }^{69}$ and the measurements on the spent catalyst confirmed that the oxidation state remained unchanged after several catalytic runs (see Fig. S3†).

In order to evaluate the catalytic activity of Ir@CTF as a TH catalyst, we considered the redox isomerisation of an allylic alcohol into the corresponding saturated carbonyl compound. Conversion of allylic alcohols into saturated ketones is usually carried out in two steps, involving sequential hydrogenation of the $\mathrm{C}=\mathrm{C}$ bonds and dehydrogenation of the alcohol, which usually requires further protection and deprotection steps. Therefore, the one-pot isomerisation represents an attractive alternative (see Scheme 1). ${ }^{70}$ This reaction can be considered as an intramolecular $\mathrm{TH}$ reaction, in which hydrogen is transferred from the alcohol moiety to the $\mathrm{C}=\mathrm{C}$ bond. Various metals from groups 8, 9, and 10 (including Ir) are known to catalyse this reaction, mostly in the form of homogeneous catalysts. ${ }^{70}$ However, a few examples exist for transition metal complexes immobilised

Table 1 Characterization of CTF and IraCTF

\begin{tabular}{lll}
\hline & $S_{\text {BET }}\left[\mathrm{m}^{2} \mathrm{~g}^{-1}\right]$ & Elemental composition $[\% \mathrm{C} / \% \mathrm{~N} / \% \mathrm{H} / \% \mathrm{Ir}]$ \\
\hline CTF & 930 & $69.7 / 27.3 / 3.0 / 0$ \\
Ir@CTF & 500 & $67.9 / 25.9 / 3.0 / 2.4$
\end{tabular}

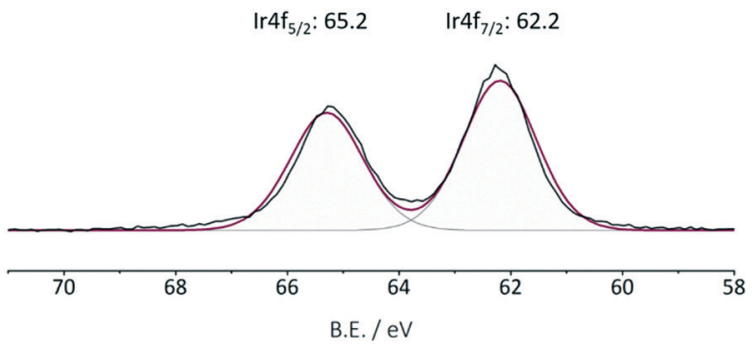

Fig. 2 Ir XPS of the fresh Ir@CTF catalyst. The oxidation state of iridium did not change after multiple catalytic runs (see Fig. S3†).

on suitable supports, such as $\mathrm{Ru}(\mathrm{OH})_{x}$ supported on alumina, ${ }^{71}$ a cationic rhodium complex supported on mesoporous silica ${ }^{72}$ and, very recently, an iridium N-heterocyclic carbene (NHC) introduced into a metal-organic framework. ${ }^{73}$ Isomerisation of allylic alcohols is usually carried out in the presence of additives, such as bases or hydrogen acceptors, to promote the reaction.

In the present study, we have selected 1-octene-3-ol as a model allylic alcohol. Then, we first brought into contact the alcohol (40 mg, $0.31 \mathrm{mmol}$ ) with the Ir@CTF material $(10 \mathrm{mg}$, corresponding to $0.40 \mathrm{~mol} \%$ Ir with respect to the substrate) in toluene $(1 \mathrm{~mL})$ at $120{ }^{\circ} \mathrm{C}$ under an inert atmosphere $\left(\mathrm{N}_{2}, 2 \mathrm{bar}\right)$. No further additives were used in the reaction. Under these conditions, a conversion of $83 \%$ of the alcohol was obtained after a reaction of $48 \mathrm{~h}$ with a $78 \%$ selectivity to the saturated ketone (final yield of $65 \%$ ). Besides 3-octanone, another product formed (in 13\% yield), which most likely corresponds to the intermediate enone (1-octen-3-one). ${ }^{70}$ Table 2 compares the performance of the Ir@CTF catalysts with those of other catalysts recently reported in the literature.

In order to improve the catalytic performance of our Ir@CTF material, we carried out a screening of various solvents. In particular, considerably better results were obtained when toluene was replaced by 2-propanol under identical conditions. Fig. 3 shows the corresponding time-conversion plot obtained.

The reaction was much faster when isopropanol was used as solvent, attaining a $98 \%$ conversion for 1-octen-3-ol after only $23 \mathrm{~h}$, with $82 \%$ yield of the target 3-octanone, resulting in a turnover frequency (TOF) of $24 \mathrm{~min}^{-1}$. As the reaction time increased, a secondary product was also observed to

a) Two-step isomerization

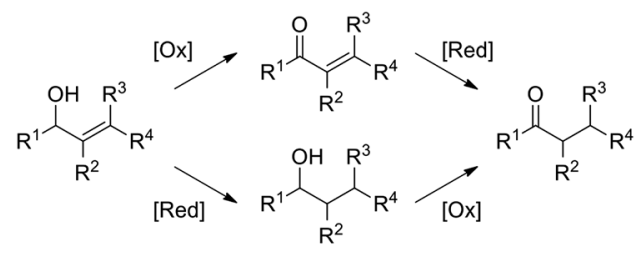

b) One-pot Isomerization

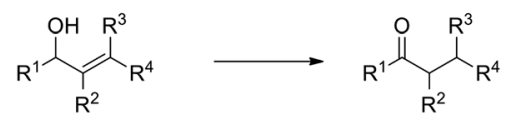

Scheme 1 Two step and one step isomerization of allylic alcohols. 
Table 2 Isomerization of 1-octen-3-ol to 3-octenone over various Ir(III) catalysts

\begin{tabular}{llllllll}
\hline Catalyst & Ir $(\mathrm{mol} \%)$ & Solvent & Temp $\left({ }^{\circ} \mathrm{C}\right)$ & $t(\mathrm{~h})$ & Yield $(\mathrm{mol} \%)$ & ${\text { TOF }\left(\mathrm{min}^{-1}\right)}^{\text {Ref. }}$ \\
\hline Ir@CTF & 0.4 & Toluene & 120 & 48 & 65 & 0.5 & This work \\
Ir@CTF & 0.4 & Toluene & 120 & 23 & 82 & 24 & This work \\
Ir-UiO-68 & 4 & Toluene & 100 & 48 & 65 & 73 \\
IrCl $_{3} \cdot 3 \mathrm{H}_{2} \mathrm{O}$ & 2 & $\mathrm{H}_{2} \mathrm{O} /$ toluene & 80 & $1.5^{b}$ & $85^{b}$ & 14 & 76 \\
$\mathrm{~K}_{3}\left[\mathrm{IrCl}_{6}\right]$ & 2 & $\mathrm{H}_{2} \mathrm{O} /$ toluene & 80 & $1.5^{b}$ & $85^{b}$ & 10 & 76
\end{tabular}

${ }^{a}$ TOF cannot be calculated from the data provided in the original paper. ${ }^{b}$ Time and yield values are estimated from the plot included in the original publication.

develop, which corresponds to the saturated alcohol, 3-octanol. This most likely originated from the further reduction of the saturated ketone through a Meerwein-PonndorfVerley TH catalysed by Ir in which isopropanol acted as the hydrogen source to form acetone. As a consequence, the overall selectivity to 3-octanone progressively decreased from $>99 \%$ at a short reaction time to $83 \%$ at the maximum conversion, which was still above the maximum selectivity obtained when toluene was used as solvent (i.e., 78\%). Note that the major by-product observed when toluene was used as solvent was the corresponding enone intermediate (1-octen-3-one), which is responsible for the relatively low selectivity attained (78\%). When isopropanol was used as solvent, accumulation of the enone in the reaction medium was no longer observed, since it was rapidly converted into the final product, 3-octanone. This may indicate that isopropanol can act as a hydrogen donor solvent, thus assisting the fast conversion of the intermediate enone into the final 3-octanone product, resulting in an overall increment of the selectivity $(83 \%)$. Given the better performance observed, all further catalytic studies were carried out in isopropanol as solvent.

According to the data shown in Fig. 3, the turnover frequency (TOF) of the Ir@CTF catalyst (calculated at a short reaction time) was $24 \mathrm{~min}^{-1}$. Although this value is far from the performance attained with various $\operatorname{Ir}(\mathrm{I})$ transition metal complexes, ${ }^{74,75}$ Ir@CTF clearly outperformed other catalysts containing $\operatorname{Ir}(\mathrm{III})$. Thus, for instance, Sasson et al. reported

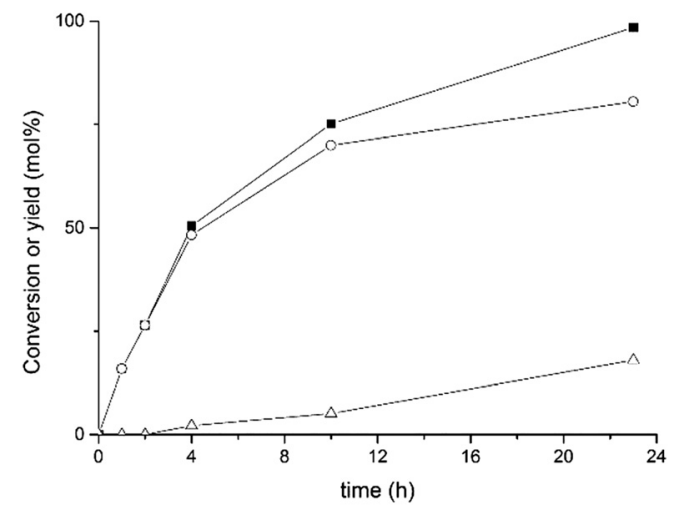

Fig. 3 Conversion of 1-octen-3-ol over IraCTF (squares) and evolution of products: 3-octanone (circles) and 3-octanol (triangles). The reaction was carried out at $120{ }^{\circ} \mathrm{C}$ under an inert atmosphere $\left(\mathrm{N}_{2}\right.$, 2 bar) using isopropanol as solvent. the conversion of the same allylic alcohol over $\mathrm{IrCl}_{3}$ and $\mathrm{K}_{3}\left[\mathrm{IrCl}_{6}\right]$ at $80{ }^{\circ} \mathrm{C}$ in a biphasic $\mathrm{H}_{2} \mathrm{O}$ /toluene system, reaching TOFs of 14 and $10 \mathrm{~min}^{-1}$, respectively. ${ }^{76}$ In a recent report by Martín-Matute and co-workers, ${ }^{73}$ a maximum yield of $65 \%$ 3-octanone was obtained after 48 h over an $\operatorname{Ir}(\mathrm{III})-\mathrm{NHC}$ complex supported in a metal-organic framework (toluene, 100 ${ }^{\circ} \mathrm{C}$ and $\left.4 \mathrm{~mol} \% \mathrm{Ir}\right)$. The catalytic results obtained with this Ir-NHC-MOF improved upon addition of bases $\left(\mathrm{NaHCO}_{3}\right.$ or $\mathrm{K}_{2} \mathrm{CO}_{3}$ ) but the amount of Ir that leached into the solution increased considerably and the crystallinity of the MOF support decreased significantly.

It is important to stress that Ir@CTF can catalyse the redox isomerisation of allylic alcohols without the need for additives. Most likely, CTF is not just an inert support to disperse the $\mathrm{Ir}^{\mathrm{III}} \mathrm{Cp}^{*}$ metal complexes. Rather, the presence of the pyridine molecules of the support $\left(\mathrm{p} K_{\mathrm{b}}=7.8\right)$ will play an active role as co-catalysts in the isomerisation reaction, by assisting in the initial alcohol deprotonation and coordination to the Ir centres to form the initial metal enolate.

Reusability studies of the Ir@CTF material using isopropanol (i-PrOH) as solvent were performed for up to six consecutive runs, and the results are shown in Fig. 4 . Between two consecutive catalytic runs, the solid was recovered by filtration, washed with i-PrOH, and dried at room temperature. Only a slight decrease of activity was observed over the first three runs (the maximum conversion after $22 \mathrm{~h}$ dropped from $99 \%$ to $97 \%$, Fig. 4), while a more pronounced decrease

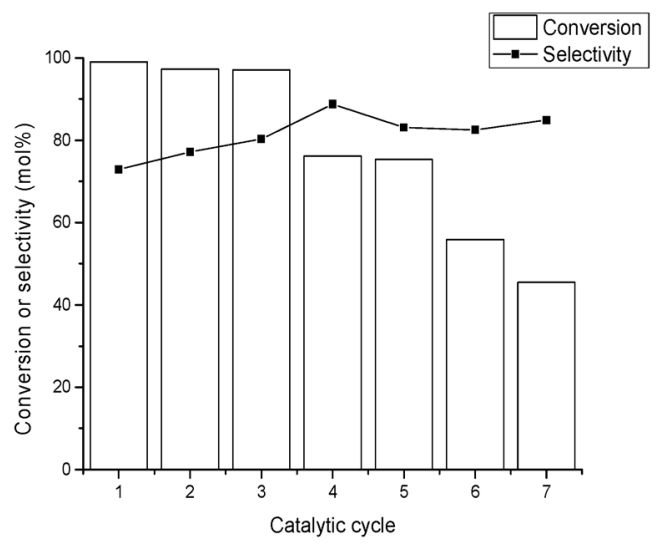

Fig. 4 Conversion and selectivity to 3-octanone for six consecutive catalytic runs. The reaction was carried out at $120^{\circ} \mathrm{C}$ under an inert atmosphere $\left(\mathrm{N}_{2}, 2\right.$ bar) using isopropanol as solvent. 
of activity was observed starting from the fourth cycle. According to XPS analysis of the material recovered after the reactions, the $3+$ oxidation state of Ir was maintained. Analysis of the filtrate after the first cycle revealed that some Ir leaches from the solid into the solution, which amounts to $3.6 \%$ of the total Ir used. This was most likely due to the additional washing during the reaction of some loosely bound Ir species in the Ir@CTF material. However, no significant amounts of Ir were detected in the filtrate after the second catalytic run $(<1 \%$ of the total $\mathrm{Ir})$. Therefore, the catalyst deactivation observed upon reuse was (mainly) attributed to a build-up of adsorbed products on the catalyst surface, progressively blocking the active sites. Meanwhile, the selectivity to the ketone was maintained (or slightly increased) upon consecutive reuses.

\section{Conclusions}

A nitrogen rich covalent framework constructed from pyridinedicarbonitrile building block allows a molecular heterogeneous catalyst to be obtained, where CTF plays the role of the scaffold and the base. The Ir@CTF catalyst allows straightforward handling and recycling under ambient conditions.

\section{Acknowledgements}

Financial support from the Generalitat Valenciana (projects Consolider-Ingenio MULTICAT and AICO/2015/065), the Spanish Ministry of Economy and Competitiveness (MINECO) (program Severo Ochoa SEV20120267), and the Spanish Ministry of Science and Innovation (MICINN) (project MAT201452085-C2-1-P) are gratefully acknowledged. This project has received funding from the European Union's Horizon 2020 research and innovation programme under the Marie Sklodowska-Curie grant agreement No 641887 (project acronym: DEFNET). Also, financial support from the European Union Seventh Framework Programme (FP7/2007-2013) under the grant agreement number 309701, project $\mathrm{Eco}^{2} \mathrm{CO}_{2}$ is acknowledged.

\section{References}

1 D. Wang and D. Astruc, Chem. Rev., 2015, 115, 6621-6686.

2 F. G. Cirujano, A. Leyva-Pérez, A. Corma and F. X. Llabrés i Xamena, ChemCatChem, 2013, 5, 538-549.

3 H. Khajavi, H. A. Stil, H. P. C. E. Kuipers, J. Gascon and F. Kapteijn, ACS Catal., 2013, 3, 2617-2626.

4 A. Corma and P. Serna, Science, 2006, 313, 332.

5 A. Azua, J. A. Mata and E. Peris, Organometallics, 2011, 30, 5532-5536.

6 A. Azua, J. A. Mata, E. Peris, F. Lamaty, J. Martinez and E. Colacino, Organometallics, 2012, 31, 3911-3919.

7 A. Azua, S. Sanz and E. Peris, Chem. - Eur. J., 2011, 17, 3963-3967.

8 A. Binobaid, M. Iglesias, D. Beetstra, A. Dervisi, I. Fallis and K. J. Cavell, Eur. J. Inorg. Chem., 2010, 2010, 5426-5431.

9 S. K. Furfari, M. R. Gyton, D. Twycross and M. L. Cole,
Chem. Commun., 2015, 51, 74-76.

$10 \mathrm{X}$. Gong, H. Zhang and X. Li, Tetrahedron Lett., 2011, 52, 5596-5600.

11 D. Gulcemal, A. G. Gokce, S. Gulcemal and B. Cetinkaya, RSC Adv., 2014, 4, 26222-26230.

12 S. Gulcemal, A. G. Gokce and B. Cetinkaya, Dalton Trans., 2013, 42, 7305-7311.

13 S. Gülcemal, A. G. Gökçe and B. Çetinkaya, Inorg. Chem., 2013, 52, 10601-10609.

14 M. V. Jiménez, J. Fernández-Tornos, J. J. Pérez-Torrente, F. J. Modrego, P. Garcı-Orduña and L. A. Oro, Organometallics, 2015, 34, 926-940.

15 M. V. Jiménez, J. Fernández-Tornos, J. J. Pérez-Torrente, F. J. Modrego, S. Winterle, C. Cunchillos, F. J. Lahoz and L. A. Oro, Organometallics, 2011, 30, 5493-5508.

16 X.-H. Zhu, L.-H. Cai, C.-X. Wang, Y.-N. Wang, X.-Q. Guo and X.-F. Hou, J. Mol. Catal. A: Chem., 2014, 393, 134-141.

17 R. Maity, S. Hohloch, C.-Y. Su, M. van der Meer and B. Sarkar, Chem. - Eur. J., 2014, 20, 9952-9961.

18 A. Ruff, C. Kirby, B. C. Chan and A. R. O'Connor, Organometallics, 2016, 35, 327-335.

19 H. Vázquez-Villa, S. Reber, M. A. Ariger and E. M. Carreira, Angew. Chem., Int. Ed., 2011, 50, 8979-8981.

20 C. Wang, A. Pettman, J. Bacsa and J. Xiao, Angew. Chem., Int. Ed., 2010, 49, 7548-7552.

21 Y. Wei, D. Xue, Q. Lei, C. Wang and J. Xiao, Green Chem., 2013, 15, 629-634.

22 X. Wu, X. Li, A. Zanotti-Gerosa, A. Pettman, J. Liu, A. J. Mills and J. Xiao, Chem. - Eur. J., 2008, 14, 2209-2222.

23 M. B. Gawande, H. Guo, A. K. Rathi, P. S. Branco, Y. Chen, R. S. Varma and D.-L. Peng, RSC Adv., 2013, 3, 1050-1054.

24 G. Liu, H. Gu, Y. Sun, J. Long, Y. Xu and H. Li, Adv. Synth. Catal., 2011, 353, 1317-1324.

25 R. B. Nasir Baig and R. S. Varma, ACS Sustainable Chem. Eng., 2013, 1, 805-809.

26 Y. Sun, G. Liu, H. Gu, T. Huang, Y. Zhang and H. Li, Chem. Commun., 2011, 47, 2583-2585.

27 N. Haraguchi, A. Nishiyama and S. Itsuno, J. Polym. Sci., Part A: Polym. Chem., 2010, 48, 3340-3349.

28 R. Marcos, C. Jimeno and M. A. Pericàs, Adv. Synth. Catal., 2011, 353, 1345-1352.

29 R. A. Molla, A. S. Roy, K. Ghosh, N. Salam, M. A. Iqubal, K. Tuhina and S. M. Islam, J. Organomet. Chem., 2015, 776, 170-179.

30 H. Sugie, Y. Hashimoto, N. Haraguchi and S. Itsuno, J. Organomet. Chem., 2014, 751, 711-716.

31 R. Wang, J. Wan, X. Ma, X. Xu and L. Liu, Dalton Trans., 2013, 42, 6513-6522.

32 X. Xu, R. Wang, J. Wan, X. Ma and J. Peng, RSC Adv., 2013, 3, 6747-6751.

33 Z. Zhou and Q. Ma, Appl. Organomet. Chem., 2011, 25, 233-237.

34 M. Gopiraman, S. G. Babu, Z. Khatri, K. Wei, M. Endo, R. Karvembu and I. S. Kim, Catal. Sci. Technol., 2013, 3, 1485-1489.

35 M. Gopiraman, S. Ganesh Babu, Z. Khatri, W. Kai, Y. A. Kim, M. Endo, R. Karvembu and I. S. Kim, J. Phys. Chem. C, 2013, 117, 23582-23596. 
36 B. Barati, M. Moghadam, A. Rahmati, V. Mirkhani, S. Tangestaninejad and I. Mohammadpoor-Baltork, J. Organomet. Chem., 2013, 724, 32-39.

37 M. Blanco, P. Álvarez, C. Blanco, M. V. Jiménez, J. Fernández-Tornos, J. J. Pérez-Torrente, L. A. Oro and R. Menéndez, ACS Catal., 2013, 3, 1307-1317.

38 M. Gopiraman, S. G. Babu, R. Karvembu and I. S. Kim, Appl. Catal., A, 2014, 484, 84-96.

39 S.-J. Chen, H.-X. You, G. Vo-Thanh and Y. Liu, Monatsh. Chem., 2013, 144, 851-858.

40 T. Cheng, J. Long, X. Liang, R. Liu and G. Liu, Mater. Res. Bull., 2014, 53, 1-6.

41 P. N. Liu, P. M. Gu, F. Wang and Y. Q. Tu, Org. Lett., 2004, 6, 169-172.

42 L.-L. Lou, H. Du, Y. Shen, K. Yu, W. Yu, Q. Chen and S. Liu, Microporous Mesoporous Mater., 2014, 187, 94-99.

43 S. M. Sarkar, M. M. Yusoff and M. L. Rahman, J. Chin. Chem. Soc., 2015, 62, 177-181.

44 Y. Shen, Q. Chen, L.-L. Lou, K. Yu, F. Ding and S. Liu, Catal. Lett., 2010, 137, 104-109.

45 D. Zhang, J. Xu, Q. Zhao, T. Cheng and G. Liu, ChemCatChem, 2014, 6, 2998-3003.

46 M. L. Kantam, B. P. C. Rao, B. M. Choudary and B. Sreedhar, Adv. Synth. Catal., 2006, 348, 1970-1976.

47 A. Corma, M. E. Domine and S. Valencia, J. Catal., 2003, 215, 294-304.

48 Y. Zhu, G. Chuah and S. Jaenicke, J. Catal., 2004, 227, 1-10.

49 A. Corma, F. X. Llabrés i Xamena, C. Prestipino, M. Renz and S. Valencia, J. Phys. Chem. C, 2009, 113, 11306-11315.

50 Y. Gao, S. Jaenicke and G.-K. Chuah, Appl. Catal., A, 2014, 484, 51-58.

51 A. M. Hengne, A. V. Malawadkar, N. S. Biradar and C. V. Rode, RSC Adv., 2014, 4, 9730-9736.

52 S. Muratsugu, Z. Weng, H. Nakai, K. Isobe, Y. Kushida, T. Sasaki and M. Tada, Phys. Chem. Chem. Phys., 2012, 14, 16023-16031.

53 K. Pupovac and R. Palkovits, ChemSusChem, 2013, 6, 2103-2110.

54 K. Shimura and K.-I. Shimizu, Green Chem., 2012, 14, 2983-2985.

55 X. Tang, L. Hu, Y. Sun, G. Zhao, W. Hao and L. Lin, RSC Adv., 2013, 3, 10277-10284.

56 S. Das, P. Heasman, T. Ben and S. Qiu, Chem. Rev., 2017, 117, 1515-1563.

57 D.-S. Zhang, Z. Chang, Y.-B. Lv, T.-L. Hu and X.-H. Bu, RSC
Adv., 2012, 2, 408-410.

58 P. Kuhn, M. Antonietti and A. Thomas, Angew. Chem., Int. Ed., 2008, 47, 3450-3453.

59 R. Palkovits, M. Antonietti, P. Kuhn, A. Thomas and F. Schüth, Angew. Chem., Int. Ed., 2009, 48, 6909-6912.

60 A. V. Bavykina, M. G. Goesten, F. Kapteijn, M. Makkee and J. Gascon, ChemSusChem, 2015, 8, 809-812.

61 A. V. Bavykina, E. Rozhko, M. G. Goesten, T. Wezendonk, B. Seoane, F. Kapteijn, M. Makkee and J. Gascon, ChemCatChem, 2016, 8, 2217-2221.

62 G. Gunniya Hariyanandam, D. Hyun, P. Natarajan, K.-D. Jung and S. Yoon, Catal. Today, 2016, 265, 52-55.

63 P. J. C. Hausoul, C. Broicher, R. Vegliante, C. Göb and R. Palkovits, Angew. Chem., Int. Ed., 2016, 55, 5597-5601.

64 K. Park, G. H. Gunasekar, N. Prakash, K.-D. Jung and S. Yoon, ChemSusChem, 2015, 8, 3410-3413.

65 M. Pilaski, J. Artz, H.-U. Islam, A. M. Beale and R. Palkovits, Microporous Mesoporous Mater., 2016, 227, 219-227.

66 E. Rozhko, A. Bavykina, D. Osadchii, M. Makkee and J. Gascon, J. Catal., 2017, 345, 270-280.

67 W.-H. Wang, M. Z. Ertem, S. Xu, N. Onishi, Y. Manaka, Y. Suna, H. Kambayashi, J. T. Muckerman, E. Fujita and Y. Himeda, ACS Catal., 2015, 5, 5496-5504.

68 M. G. Goesten, P. C. M. M. Magusin, E. A. Pidko, B. Mezari, E. J. M. Hensen, F. Kapteijn and J. Gascon, Inorg. Chem., 2014, 53, 882-887.

69 F. Angersbach-Bludau, C. Schulz, J. Schoffel and P. Burger, Chem. Commun., 2014, 50, 8735-8738.

70 N. Ahlsten, A. Bartoszewicz and B. Martin-Matute, Dalton Trans., 2012, 41, 1660-1670.

71 K. Yamaguchi, T. Koike, M. Kotani, M. Matsushita, S. Shinachi and N. Mizuno, Chem. - Eur. J., 2005, 11, 6574-6582.

72 S. Sahoo, H. Lundberg, M. Edén, N. Ahlsten, W. Wan, X. Zou and B. Martín-Matute, ChemCatChem, 2012, 4, 243-250.

73 F. Carson, E. Martinez-Castro, R. Marcos, G. G. Miera, K. Jansson, X. Zou and B. Martín-Matute, Chem. Commun., 2015, 51, 10864-10867.

74 R. C. van der Drift, E. Bouwman and E. Drent, J. Organomet. Chem., 2002, 650, 1-24.

75 R. Uma, C. Crévisy and R. Grée, Chem. Rev., 2003, 103, 27-52.

76 Y. Sasson, A. Zoran and J. Blum, J. Mol. Catal., 1981, 11, 293-300. 